\title{
Consumer Preference and Willingness to Pay for Direct-to-Consumer Mobile Teledermoscopy Services in Australia
}

\author{
Centaine L. Snoswell ${ }^{a, b}, c$ Jennifer A. Whittyc, d Liam J. Caffery ${ }^{a, b}$ Joanna Kho ${ }^{f}$ \\ Caitlin Horsham $^{b, g}$ Lois J. Loescher ${ }^{e}$ Dimitrios Vagenas $^{j} \quad$ Nicole Gillespie $^{f}$ \\ H. Peter Soyer ${ }^{\text {h, }}$ Monika Jandab, g
}

${ }^{a}$ Centre for Online Health, The University of Queensland, Brisbane, QLD, Australia; ${ }^{b}$ Centre for Health Services Research, The University of Queensland, Brisbane, QLD, Australia; 'School of Pharmacy, The University of

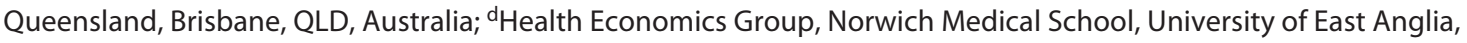
Norwich, UK; ${ }^{e}$ College of Nursing, Arizona Cancer Center, and Skin Cancer Institute at The University of Arizona, Tucson, AZ, USA; fUQ Business School, The University of Queensland, Brisbane, QLD, Australia; 9Institute of Health and Biomedical Innovation, School of Biomedical Sciences, Queensland University of Technology, Brisbane, QLD,

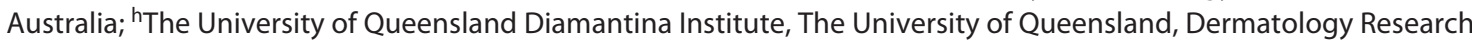
Centre, Brisbane, QLD, Australia; 'Dermatology Department, Princess Alexandra Hospital, Brisbane, QLD, Australia; IInstitute of Health and Biomedical Innovation, Directorate, Queensland University of Technology, Brisbane, QLD, Australia

\section{Keywords}

Cancer · Choice experiment · Dermoscopy · Melanoma ·

Questionnaire $\cdot$ Teledermoscopy

\begin{abstract}
Objective: To investigate consumer preference and willingness to pay for mobile teledermoscopy services in Australia. Methods: Consumers who were taking part in a randomised controlled trial comparing mobile teledermoscopy and skin self-examination were asked to complete a survey which incorporated a discrete choice experiment (DCE) and a contingent valuation question. Responses were used to determine their willingness to pay for mobile teledermoscopy services in Australia and their overall service preferences. Results: The 199 consumers who responded were $71 \%$ female and had a mean age of 42 years (range, 18-73). The DCE results
\end{abstract}

showed that consumers prefer a trained medical professional to be involved in their skin cancer screening. Consumers were willing to pay AUD 41 to change from a general practitioner reviewing their lesions in-person to having a dermatologist reviewing the teledermoscopy images. Additionally, they were willing to pay for services that had shorter waiting times, that reduced the time away from their usual activities, and that have higher accuracy and lower likelihood of unnecessary excision of a skin lesion. When asked directly about their willingness to pay for a teledermoscopy service using a contingent valuation question, the majority (73\%) of consumers selected the lowest two value brackets of AUD 1-20 or AUD 21-40. Conclusion: Consumers are willing to pay out of pocket to access services with attributes such as a dermatologist review, improved accuracy, and fewer excisions. (c) 2021 The Author(s)

Published by S. Karger AG, Basel karger@karger.com www.karger.com/drm

Karger $\stackrel{\text { ' }}{5}$

BOPEN ACCESS
(C) 2021 The Author(s)

Published by S. Karger AG, Basel

This is an Open Access article licensed under the Creative Commons Attribution-NonCommercial-4.0 International License (CC BY-NC) (http://www.karger.com/Services/OpenAccessLicense), applicable to the online version of the article only. Usage and distribution for commercial purposes requires written permission.
Correspondence to:

Centaine L.Snoswell, c.snoswell@uq.edu.au 


\section{Introduction}

In Australia, skin cancer is a significant contributor to the national burden of disease [1]. Aside from primary prevention, early detection leading to diagnosis and treatment is a key strategy to reduce skin cancer-related morbidity and mortality [2,3]. Direct-to-consumer technologies, such as direct-to-consumer teledermoscopy, can be used to increase access to timely detection and diagnostic services, and therefore could have a role in preventing skin cancer-related morbidity and mortality [4]. Teledermoscopy involves the consumer capturing an image of a skin lesion that they are concerned about using a smartphone with an attached dermoscope, and sending it with relevant clinical information for a store-and-forward teledermatology consultation. Teledermoscopy therefore enables improved and expedited access to specialist advice without the travel or delay to appointment associated with conventional in-person visits. Previous literature examining the effectiveness of store-and-forward teledermatology (without a dermoscopic device) and teledermoscopy (with a dermoscopic device) has demonstrated comparable clinical accuracy to in-person consultation $[5,6]$.

Consumer preferences for alternate models of care delivery, such as teledermoscopy, play a big role in their successful implementation and uptake [4]. Direct-to-consumer teledermoscopy service models have been investigated internationally, with research focusing on commercial services and their clinical characteristics [710]. Previous Australian research has demonstrated that consumers have a preference for some of the attributes of teledermoscopy compared to in-person services such as specialist dermatologist access; however, previous research has been conducted with small sample populations [11-13]. These preliminary Australian studies have shown that consumers are potentially willing to pay for the attributes of direct-to-consumer teledermoscopy that they desire, but these results have not been confirmed in large-scale trials $[11,12,14]$.

Methods for assessing consumer preferences and willingness to pay for services have been ported from other fields, such as economics, to the field of healthcare where they are now routinely used [15]. These include discrete choice experiments (DCEs), where consumer preference for various aspects of a particular service model can be quantified comparative to other service elements. Marginal utility values, marginal willingness to pay, and the probability of the new service taking a share of the market can all be estimated using this technique. The aim of this study was to determine consumer preferences for different at- tributes of direct-to-consumer teledermoscopy services and their willingness to pay for those service attributes. This paper extends previous work $[11,12]$ by presenting results from a larger group of respondents who participated in a randomised trial and had experience with teledermoscopy over a longer period, and by investigating consumer willingness to pay using multiple methods.

\section{Subjects and Methods}

A survey consisting of a DCE, developed previously [11, 12], and a contingent valuation question was administered to 199 consumers as part of a randomised controlled trial comparing skin self-examination and teledermoscopy-assisted skin self-examination $[16,17]$. A DCE instrument is a specific set of questions where consumers are presented with, and asked to make choices between, mutually exclusive options (in this case skin cancer examination services) containing different levels of predefined attributes. The DCE method is based on random utility theory, which assumes that individuals make rational choices to optimise their own utility, and therefore their responses can be used to estimate their preferences for different services and attributes presented to them in the choice set [18]. The DCE elicits consumer preference between attributes and their levels which can be translated to a willingnessto-pay value for a service. In contrast, the contingent valuation question is a stated preference method that directly asks what the consumer would be willing to pay. The use of DCEs to elicit preferences in healthcare has been used since the original proposition by McFadden in the 1970s [19].

DCE and contingent valuation methods are both stated preference methods for determining willingness to pay, and these were used in this survey to determine consumer preferences and willingness to pay for mobile direct-to-consumer teledermoscopy [18, $20-22]$. It is known that consumers do not always answer in a manner that accurately reflects their spending when asked directly what they would be willingness to pay for goods [23]. Since we do not have access to revealed preference information in the form of market data, multiple question methods were included in this research to investigate consumer-stated willingness to pay, and the findings from each were compared.

\section{Survey Development and Sample Size}

The design, development, and piloting of the DCE instrument has been reported elsewhere $[11,12]$. Each DCE choice task included two service options that had varying attributes and levels, an option to "perform a skin self-examination" without cost, and an option to do no skin examination (choice set example in Fig. 1). The DCE tool was designed to be D-efficient and was broken into two blocks of questions so that respondents only had to answer twelve scenario questions each. To ensure that only realistic choice sets were presented the design included two constraints: (1) only an in-person consultation could have a $<4 \mathrm{~h}$ wait time for results, and (2) mobile teledermoscopy was only reviewed by a dermatologist while general practitioner (GP) review only occurred when consumers selected the "visit a skin cancer clinic or GP" option.

The contingent valuation question asked "How much would you be willing to pay to use mobile teledermoscopy for feedback on one 
Fig. 1. Block 1, choice set 1 - example discrete choice experiment questions. GP, general practitioner.

\begin{tabular}{|c|c|c|c|c|}
\hline \multirow[t]{3}{*}{$\begin{array}{l}\text { Attributes } \\
\text { (constant) }\end{array}$} & \multicolumn{4}{|c|}{ Choices } \\
\hline & \multicolumn{4}{|c|}{ 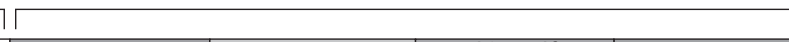 } \\
\hline & Health service $A$ & Health service B & $\begin{array}{l}\text { Skin self- } \\
\text { examination }\end{array}$ & None \\
\hline $\begin{array}{l}\text { Method of } \\
\text { screening }\end{array}$ & $\begin{array}{l}\text { visit a skin } \\
\text { cancer clinic }\end{array}$ & $\begin{array}{l}\text { diagnosis using } \\
\text { a phone camera }\end{array}$ & \multirow[t]{6}{*}{$\begin{array}{l}\text { skin self- } \\
\text { examination }\end{array}$} & \multirow{6}{*}{$\begin{array}{l}\text { I would not } \\
\text { perform a } \\
\text { routine skin } \\
\text { check }\end{array}$} \\
\hline $\begin{array}{l}\text { Time away from } \\
\text { usual activities } \\
\text { including travel }\end{array}$ & $\begin{array}{l}\text { more than } \\
4 \text { hours }\end{array}$ & $\begin{array}{l}\text { more than } \\
4 \text { hours }\end{array}$ & & \\
\hline $\begin{array}{l}\text { Chance of accurately } \\
\text { diagnosing a skin } \\
\text { lesion }\end{array}$ & $65-75 \%$ & $65-75 \%$ & & \\
\hline $\begin{array}{l}\text { Wait time to get } \\
\text { result }\end{array}$ & up to 1 day & up to 3 days & & \\
\hline $\begin{array}{l}\text { Who reviews the } \\
\text { result }\end{array}$ & $\begin{array}{l}\text { GP performing } \\
\text { the service }\end{array}$ & a dermatologist & & \\
\hline $\begin{array}{l}\text { Number of non- } \\
\text { cancerous lesions } \\
\text { removed to detect } \\
\text { one skin cancer }\end{array}$ & $\begin{array}{l}10 \text { removed to } \\
\text { detect one skin } \\
\text { cancer }\end{array}$ & $\begin{array}{l}3 \text { removed to } \\
\text { detect one skin } \\
\text { cancer }\end{array}$ & & \\
\hline \multirow[t]{3}{*}{ Out of pocket cost } & AUD 60 & AUD 0 & AUD 0 & AUD 0 \\
\hline & \multicolumn{4}{|c|}{$\|$} \\
\hline & \multicolumn{2}{|c|}{$\begin{array}{c}\text { Levels } \\
\text { (vary in each choice set) }\end{array}$} & \multicolumn{2}{|c|}{$\begin{array}{l}\text { Opt-out options } \\
\text { (constant) }\end{array}$} \\
\hline
\end{tabular}

suspicious mole or skin spot?" Consumers were presented with multiple-choice options in AUD 20 increments from AUD 0 to AUD 101+; a "not willing to pay" and "other" option were also available. Consumers were not asked how much they would be willing to pay for the device. The consistency of willingness to pay estimates was compared between the DCE and contingent valuation approaches.

The sample size for the randomised controlled trial was calculated to detect the primary clinical outcome, and the 199 consumers (100\% DCE completion rate) who participated in the trial survey represent an amply sufficient sample size for the DCE according to the Johnson and Orme rule of thumb formula $(n \geq 62.5$ for this DCE) [24].

\section{Consumer Recruitment and Data Collection}

Consumers were sourced from the SKin INnovation (SKIN) randomised controlled trial and included individuals who volunteered from the general population and who owned an iPhone; they were excluded from participation if they had had a melanoma diagnosis in the previous 5 years $[16,17]$. Consumers were asked to perform a skin self-examination (randomised to do this either with or without teledermoscopy) once a month for 3 months, after which they visited a dermatologist for an in-person full-body examination. At the 3-month follow-up $100 \%$ of the consumers who participated in the trial completed the DCE and contingent valuation as part of the final follow-up survey, which took 20-30 min.

The SKIN trial was registered prospectively with the Australian and New Zealand Clinical Trials Registry (Registration No.: ACTRN12616000989448). The trial protocol, registration, and primary clinical results have been reported elsewhere $[13,16]$. Preliminary results of the pilots for the DCE task in smaller populations have been presented previously $[11,12]$.

\section{Data Analysis}

All analyses were undertaken in STATA (v16.0). The DCE data were analysed using a mixed logit regression model (with the Stata user-written-command "mixlogit"[25]) with attribute levels specified using dummy coding except for the cost attribute, for which a continuous effect was assumed. The skin self-examination and no skin examination options were specified to have a constant (fixed) effect. Fixed parameters were specified as cost and opt-out options from each choice set, all other variables were run "random" variables which assumed that the preferences were normally distributed across the cohort derived from 50 Halton draws. Heterogeneity was investigated by examining the relative magnitude of the standard deviation compared to the coefficient [25].

Willingness to Pay for Attributes Estimated from the DCE. Marginal willingness to pay was calculated by examining the coefficients for each attribute level relative to its base attribute level and the coefficient for the cost attribute [26]. Values were calculated with the Stata wtp [27] user-written-command.

Contingent Valuation Question. Responses to the contingent valuation question were plotted graphically and free-text responses were quoted.

\section{Results}

\section{Consumer Characteristics}

Of the 199 study consumers who responded to the survey, half $(n=98)$ were randomised to use a teledermoscopy device to assist them with their skin self-examination 
Table 1. Mixed logit model outputs $(N=199)$

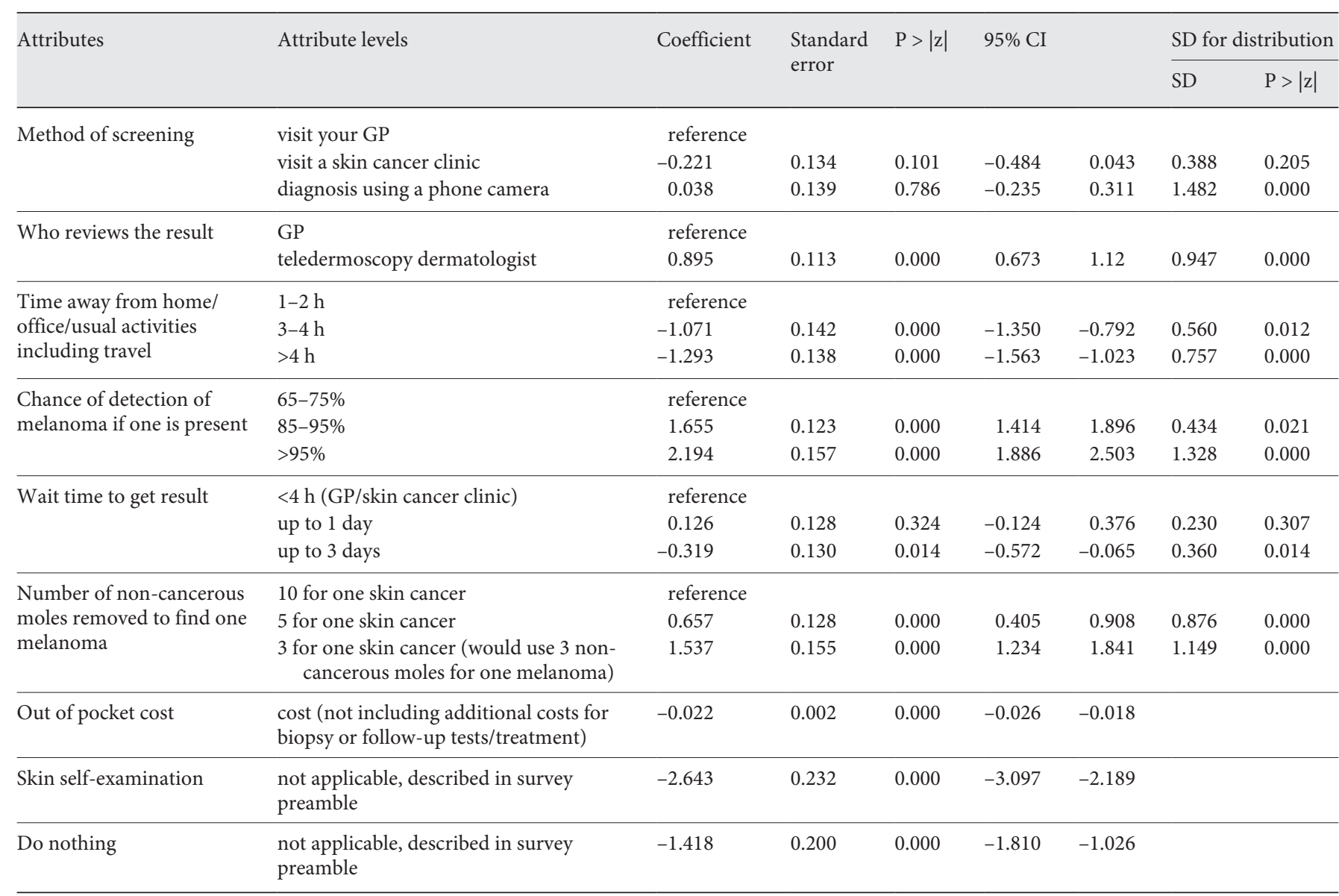

Model fit characterised by an Akaike information criterion of 3,472 and a Bayesian information criterion of 3,554. CI, confidence interval; GP, general practitioner; SD, standard deviation.

within the trial and the other half $(n=101)$ conducted unaided skin self-examination. Consumers were $71 \%$ female $(n=141)$ and had an average age of 42 years (range, 18-73).

\section{Consumer Preferences}

Table 1 presents the mixed logit model of the DCE data. Consumers selected to either perform a skin selfexamination in $2 \%$ of the twelve DCE scenario questions they responded to, and selected the option to do nothing for approximately $7 \%$ of the twelve scenarios. Consistent with expectations, consumers preferred a lower-cost service with shorter waiting times for results and services which required the least amount of time away from their usual activities $(p<0.0001)$. Additionally, patients preferred services that offered the highest chance of detecting a melanoma and those which required the lowest number of excisions to confirm detection $(p<0.0001)$.
Consumers preferred any form of screening service over performing a skin self-examination $(p<0.0001)$ or doing nothing $(p<0.0001)$. This demonstrates that overall, consumers prefer the involvement of a trained medication professional to assist with their skin cancer screening. If provided with the option, consumers would prefer to have a dermatologist review their teledermoscopy results rather than seeing a GP or having a GP review their results $(p<0.0001)$. When an interaction term was included in the model for which arm of the trial the responding patient was in (teledermoscopy or no teledermoscopy), the preference for a dermatologist review through teledermoscopy rather than a GP appeared to increase slightly in the patients who experienced directto-consumer teledermoscopy during the trial; however, this was not statistically significant (online suppl. Table S1, see www.karger.com/doi/10.1159/000517257). 
Table 2. Marginal willingness to pay for marginal improvement in service attributes of teledermoscopy services, estimated from the discrete choice experiment

\begin{tabular}{|c|c|c|}
\hline Service attribute & Marginal change in service & $\begin{array}{l}\text { Marginal willingness } \\
\text { to pay (AUD) }\end{array}$ \\
\hline \multirow[t]{2}{*}{ Method of screening } & $\begin{array}{l}\text { change from GP in person to diagnosis using a phone } \\
\text { camera (dermatologist via mobile teledermoscopy) }\end{array}$ & $1.73(-10.78 \text { to } 14.25)^{\mathrm{a}}$ \\
\hline & change from GP in person to visit a skin cancer clinic & $-10.12(-22.06 \text { to } 1.82)^{\mathrm{a}}$ \\
\hline Who reviews the results & $\begin{array}{l}\text { change from GP in person to diagnosis using a phone } \\
\text { camera (dermatologist via mobile teledermoscopy) }\end{array}$ & $41.01(28.56$ to 53.46$)$ \\
\hline \multirow{2}{*}{$\begin{array}{l}\text { Time away from home/office/ } \\
\text { usual activities including travel }\end{array}$} & change time away from usual activities from $1-2 \mathrm{~h}$ to $4+\mathrm{h}$ & $-59.26(-74.38$ to -44.14$)$ \\
\hline & change time away from usual activities from $1-2 \mathrm{~h}$ to $3-4 \mathrm{~h}$ & $-49.07(-64.25$ to -33.89$)$ \\
\hline \multirow{2}{*}{$\begin{array}{l}\text { Chance of detection of melanoma if one is } \\
\text { present }\end{array}$} & increase chance from $65 \%$ to $75-95 \%+$ & $100.56(77.16$ to 123.96$)$ \\
\hline & increase chance from $65-75 \%$ to $85-95 \%$ & $75.85(58.12$ to 93.58$)$ \\
\hline \multirow{2}{*}{$\begin{array}{l}\text { Number of non-cancerous moles removed } \\
\text { to find one melanoma }\end{array}$} & reduce excised benign lesions from 10 to 3 & $70.46(52.52$ to 88.40$)$ \\
\hline & reduce excised benign lesions from 10 to 5 & $30.09(18.67$ to 41.51$)$ \\
\hline
\end{tabular}

GP, general practitioner. ${ }^{\text {a }}$ Willingness to pay estimates based on non-significant attribute coefficients.

The model coefficients for the method of screening (in-person visit with a GP or specialist GP or use of teledermoscopy with dermatologist review of pictures) were not statistically significant. Thus, we did not observe a difference in consumer preferences for different screening methods (output coefficients were not significant and the standard deviations for the distribution were large relative to the coefficients and non-significant). The coefficient for the mid-range wait time variable ( $<4 \mathrm{~h}$ but up to 1 day wait for results) was not statistically significant either; thus, whilst reducing wait time for results from up to 3 days to $<4 \mathrm{~h}$ was meaningful $(p=0.014)$, we did not observe a preference to reduce results from up to 1 day to $<4 \mathrm{~h}(p=0.324)$.

Preference heterogeneity was observed for most of the variables within the model. The attribute levels with standard deviations $>0.8$ were all statistically significant; these include who reviews the screening results, the chance of detection for a single melanoma, and the number of noncancerous moles removed to find one melanoma. Examining the size of the standard deviation relative to the coefficient, it can be calculated that $83 \%$ of consumers would prefer a dermatologist to review their results through a direct-to-consumer teledermoscopy service rather than see their GP for an in-person screening. The heterogeneity was smaller for the chance of detection for a single melanoma, with $95 \%$ preferring an accuracy rate of $95 \%$ or higher when compared to the other options (65-75\% and $85-95 \%)$. However, 23\% of consumers would prefer to have five non-cancerous moles removed instead of ten to find a single melanoma, and $91 \%$ would prefer three compared to ten.

\section{Willingness to Pay Estimated from the DCE}

Consumer marginal willingness to pay was estimated for individual service attribute changes such as reducing the time away from usual activities from $>4 \mathrm{~h}$ to 1-2 h (Table 2). Consumers were willing to pay AUD 41 to change from a GP reviewing their lesions in person to having a dermatologist reviewing the teledermoscopy images. Other service attributes that consumers were willing to pay the most for were increased diagnostic accuracy (AUD 101 to increase from 65-75 to $>95 \%$ ), to reduce their time away from usual activities (AUD 49 to reduce from $>4 \mathrm{~h}$ to $1-2 \mathrm{~h}$ ), and to reduce the number of non-cancerous moles required to be removed to find one melanoma (AUD 71 to reduce from ten to three). 


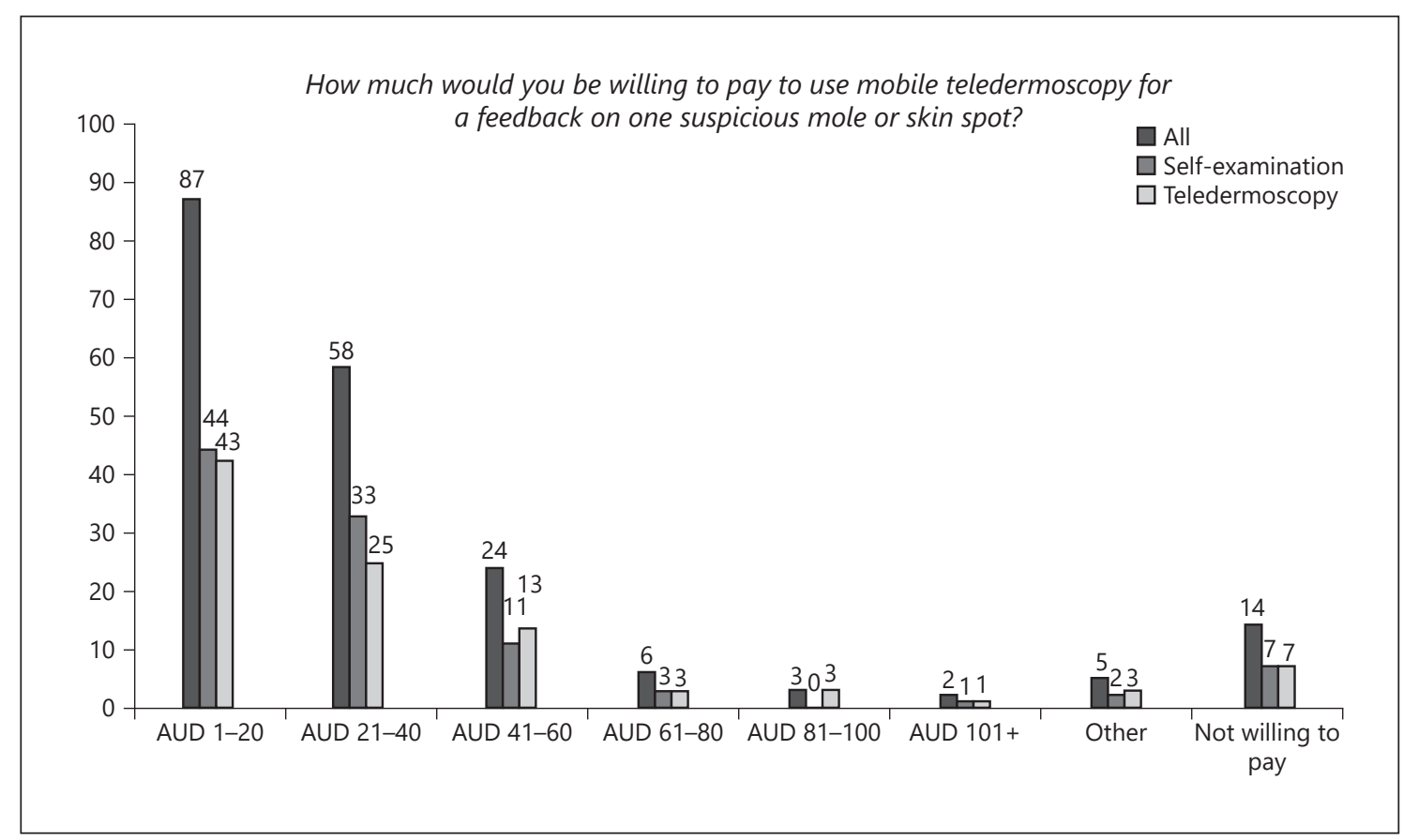

Fig. 2. Contingent valuation responses for all consumers $(n=199)$, for those who performed self-examination $(n=98)$, and for those who used mobile teledermoscopy $(n=101)$.

\section{Contingent Valuation Question}

The majority of consumers $(n=145,73 \%)$ selected the lowest two value brackets of AUD 1-20 ( $n=87,44 \%)$ or AUD 21-40 ( $n=58,29 \%)$ (Fig. 2), suggesting most would be willing to pay less than AUD 40 to use mobile teledermoscopy for feedback on one suspicious mole or skin spot. About a quarter of consumers $(n=54,27 \%)$ indicated that they would be willing to pay more that AUD 40 to receive diagnostic information for a self-selected suspicious mole or skin spot via direct-to-consumer teledermoscopy. Unlike the DCE where consumers valued the attributes of the service without considering the number of moles they needed examined, in this question consumers were valuing the service for a single-mole review.

Data were separated to explore the effect of consumer experience with direct-to-consumer teledermoscopy on willingness to pay. Responses were divided based on the trial arms: those who performed skin self-examination and those who had the opportunity to use the mobile teledermoscopy device attachment and app. There was little difference between the two groups overall.

There were four consumers who selected "other" for the contingent valuation question, most of whom stated that they would like more specific information about the different service options prior to making a selection, es- pecially with regard to government reimbursement (Table 3). Fourteen consumers indicated that they would not be willing to pay for a direct-to-consumer teledermoscopy service, seven from each trial arm. Nine of these consumers provided a comment or reason to accompany their response (Table 3). Most indicated an opinion that health services should be subsidised or free because seeing a GP is free, while others commented that they would like more information or would prefer a full skin check in-person with a dermatologist.

\section{Discussion}

Our findings demonstrate that consumers prefer any form of screening service that involves a health professional instead of performing a skin self-examination themselves or no screening at all. Australian consumers also prefer some of the service attributes offered by directto-consumer teledermoscopy over those offered to them by current standard in-person care. For example, consumers prefer a service that provides less time away from usual activities, has a dermatologist review images of skin lesions, provides a timely diagnosis, increases diagnostic accuracy, and reduces non-malignant excisions. Con- 
Table 3. Free-text responses from participants who stated that they would prefer not to pay for mobile teledermoscopy

"Can see a GP for a skin check without paying."

"I think it should be covered under Medicare."

"I think that if you want people to be healthier and encourage them to check their skin it should be free. I might not check my skin if I had to pay."

"I think this service should be available at a doctors surgery and performed by someone familiar with the technology and who is able to get all the spots that are difficult for me to get to. This should be a standard part of Medicare. Also not everyone needs to have one of these devices to use once or twice a year."

"I'd be willing to pay to purchase the mobile camera device if it was a recommendation by the dermatologist, but I would expect I would not have to pay extra then to send photos and discuss these with the dermatologist as part of a regular screening process. I do not see the two (face-to-face and self-examination) being mutually exclusive and would want to do them together as part of an overall examination process. ... Certainly the visibility of the moles was much clearer, but it is still just me interpreting it. I'd rather have an expert look at it too in order to be $100 \%$ sure."

"It should be a government-subsidised offer when this problem is a growing epidemic."

"It should be covered by the public health service as skin checks are covered."

"There are apps through health organisations that are free and works well [like] SkinVision."

"Should be bulk billed on age pension."

GP, general practitioner.

sumer were willing to pay for these attributes. We identified, using a DCE, that they were willing to pay AUD 41 for dermatologist review, AUD 101 for increased diagnostic accuracy, AUD 49 for less time away from usual activities, and AUD 71 for reduced excision rates.

We identified, using contingent valuation, that most consumers $(90 \%)$ were willing to pay out of pocket to receive diagnostic information from a dermatologist via a direct-to-consumer teledermoscopy service, and of these most (73\%) were willing to pay less than AUD 40 and the remaining 27\% were willing to pay more than AUD 40. While the DCE estimated that the respondent consumers were willing to pay at approximately AUD 41 to change from an in-person GP consultation to using a smartphone camera to consult with a dermatologist via teledermoscopy. These figures overlap with dermatologists' remuneration expectations that have previously been investigated. We previously reported that half of dermatologists interviewed ( $n=14$ ) would expect to be remunerated between AUD 1-60 $(n=6)$ and the other half would expect AUD 61-120 per teleconsultation of single skin lesion $(n=8)$ [28]. This provides evidence that the payer and provider parties have similar expectations, but that dermatologist expect slightly higher reimbursement rates than consumers have indicated they are willing to pay. Provider expectations could potentially be met with a combination of payers (i.e., private health insurance, government, and patient).

Designing and implementing a new service available to consumers, whether from a government, health provider, or commercial perspective, requires insight into consumer preferences for use. This study has provided important insight into the attributes of consumers' preferences in a direct-to-consumer teledermoscopy service and what their preferences translate to in terms of tangible economic value, e.g., consumer co-payment levels for government schemes, or by commercial entities to develop a desirable product with a viable business case.

The findings from the present study are more definitive than those of the previous pilots for the DCE question set due to the larger more inclusive population and the addition of a contingent valuation question and free-text responses. Furthermore, this study is unique because it examines consumer preference for diagnosis and referral via direct-to-consumer teledermoscopy [11, 12]. Our findings are consistent with studies that examined consumer acceptance, such as the study by Horsham et al. [14] and the DCE pilot study by Spinks et al. [11] and Snoswell et al. [12] All studies show that consumers valued some aspects of care that could be provided by directto-consumer teledermoscopy. Similarly, a study by Wu et al. [29] examined the feasibility of teledermoscopy and 
found that consumers were receptive to using it for monitoring.

Previous research has demonstrated that teledermoscopy for suspected skin cancer would cost the Medicare Benefits Scheme (Australia's universal health insurer) an extra AUD 2 for each day patients did not have to wait for a diagnosis or excision [30]. Consumers had a marginal willingness to pay of AUD 14.60 to reduce their wait time for diagnosis from 3 days to $4 \mathrm{~h}$ (Table 1 ). This equates to approximately AUD 5 per day of wait time, assuming that the final $4 \mathrm{~h}$ of wait time do not represent a meaningful period of time to consumers (i.e., their willingness to pay would be the same to reduce from 3 days to $2 \mathrm{~h}$ rather than $4 \mathrm{~h}$ ). This shows that in addition to valuing health professional involvement in their care, consumers want services that are responsive and provide them with timely results. They are also willing to pay more per day of reduced waiting time than it has been estimated that teledermoscopy will cost the Australian health system per reduced day of waiting (AUD 2 [30]) if implemented.

\section{Strengths and Limitations}

The study has several strengths, including a substantial sample of consumers, half of whom had experience with teledermoscopy for at least 3 months, and a high survey completion rate. However, given that consumers volunteered to participate in the trial by responding to media advertisements, it is likely that the trial (from which $100 \%$ of DCE respondents were sourced) attracted a proactive population who had an interest in their own skin cancer risk. This may mean that the proportion of individuals who would prefer not to be proactive or to complete a skin self-examination were underrepresented in the sample compared to the general population. The DCE findings suggest that consumers preferred diagnosis by a dermatologist via direct-to-consumer teledermoscopy rather than by a GP. Survey attributes did not include any options for consulting a dermatologist via any means other than teledermoscopy (in-person or videoconference) or for a GP consultation via a store-and-forward mechanism. Additionally, the contingent valuation question did not define all of the elements of the teledermoscopy service (i.e., accuracy or wait time) in the specific way that the DCE questions did, which may reduce the direct comparability of the responses with the findings from the DCE. It should also be noted that consumers were not asked how much they would be willing to pay for the device, which is an area that future studies could explore.

Stated preference methods such as DCEs provide insight for choices consumers say they would make be- tween hypothetical services. However, they are limited by the fact that consumer-stated preferences do not always align with their actual market behaviour [18, 31]. Valuing health services using stated preference methods is complicated further in a country like Australia because the national health system covers the cost of most essential health-related services. As demonstrated by the free-text responses by individuals who said they would not be willing to pay for services $(n=10)$, some consumers strongly believe that healthcare should be free. This phenomenon is further compounded by the fact that we asked individuals to value a preventative health service focused on detecting disease, rather than a treatment for a condition that is tangible and has current impact on their lives. As such, individuals may have felt less inclined to pay for a service if they perceived that doing nothing would be preferable for them and this action was not likely to result in a cancer diagnosis. Alternately, consumers could be asked to indicate their willingness to pay in the context of a co-payment, which may be more applicable to the Australian system and subsequently easier for consumers to value.

\section{Conclusion}

Overall the results for this research offer a valuable insight into consumer preferences and willingness to pay for teledermoscopy in Australia. Based on the estimates for willingness to pay and other questions, Australian consumers seem to prefer a number of the service attributes offered by direct-to-consumer teledermoscopy (like dermatologist involvement and reduced time away from usual activities). They are willing to pay out of pocket to access services which incorporate attributes such as a dermatologist, improved accuracy, and fewer excisions regardless of the mode of delivery. This research indicates that if consumers were making the decisions, they would consider adding direct-to-consumer teledermoscopy services as a supplement to the current service as it enables less time away from usual activities while maintaining health professional involvement in skin self-examination.

\section{Key Message}

Consumers are willing to pay out of pocket to access certain teledermatology services. 


\section{Acknowledgements}

Thank you to Jean Spinks who provided support by allowing her DCE tool to be used and providing input during analysis. We would like to thank the research staff Naomi Stekelenburg, Marko Simunovic, and Montana O'Hara, and the clinicians who assisted the dermatologist with the clinical skin examinations, Antonia Laino, Sharon Gabizon, Lena Von Schuckmann, My Co Tran, and Priyamvada Sobarun.

\section{Statement of Ethics}

Subjects provided electronic written informed consent to participate in this research. Ethics approval was granted by the Queensland University of Technology Human Research Ethics Committee (ID 1400000807).

\section{Conflict of Interest Statement}

H.P. Soyer reports grants from Medical Research Future Fund; is a shareholder of MoleMap New Zealand and e-derm consult $\mathrm{GmbH}$, and undertakes regular teledermatological reporting for both companies; is a medical consultant for Canfield Scientific and MetaOptima Technology; is a medical adviser for First Derm, and has a medical advisory board appointment with MoleMap New Zealand. All other authors declare no competing interests. FotoFinder Systems GmbH were involved in the development of the mobile teledermoscopy app used in this study.

\section{Funding Sources}

This study was done as part of a National Health and Medical Research Council (NHMRC) partnership research project on behalf of Queensland University of Technology and The University of Queensland, in partnership with FotoFinder Systems GmbH, the Princess Alexandra Hospital Foundation, Melanoma Patients Australia, Queensland Institute of Dermatology, Skin \& Cancer Foundation Australia, and the Dermatology Departments of the University of Graz, University of Arizona, and Memorial Sloan Kettering Cancer Center. This study was funded by a research grant awarded to M. Janda from the NHMRC (APP1113962). M. Janda is funded by a NHMRC Translating Research Into Practice fellowship (APP1151021). H.P. Soyer is funded by a Medical Research Future Fund Next Generation Clinical Researchers Program Practitioner fellowship (APP1137127). L.J. Loescher has partial support from the University of Arizona Cancer Center Support (NIH/NCI 5P30 CA023074-36). J.A. Whitty is supported by the National Institute for Health Research Applied Research Collaboration East of England.

\section{Author Contributions}

All authors made contributions to the development of the trial protocol and were involved in drafting the manuscript or revising it critically for important intellectual content. C.L. Snoswell conducted the data analysis and write-up with oversight from J.A. Whitty and L.J. Caffery. M. Janda is the overall chief investigator for the randomised controlled trial from which consumers were sourced. H.P. Soyer provides dermatological expertise, including providing teledermoscopy reports of all study lesions and performing all clinical skin examinations. D. Vagenas provided general statistical expertise for the primary randomised controlled trial. N. Gillespie and J. Kho examined pathways to integrate mobile teledermoscopy into practice and business models for teledermoscopy. L.J. Loescher provided oversight and critical review. C. Horsham was one of the project coordinators. All authors gave final approval of this paper.

\section{References}

1 Sanofi Australia. The burden of non-melanoma skin cancer (NMSC) in Australia. Online Sanofi (supported by Rare Cancers Australia), 2020.

2 Youl PH, Youlden DR, Baade PD. Changes in the site distribution of common melanoma subtypes in Queensland, Australia over time: implications for public health campaigns. $\mathrm{Br}$ J Dermatol. 2013;168(1):136-44.

3 Fong Z, Tanabe K. Comparison of melanoma guidelines in the USA, Canada, Europe, Australia and New Zealand: a critical appraisal and comprehensive review. Br J Dermatol. 2014;170(1):20-30.
4 Horsham C, Snoswell C, Vagenas D, Loescher LJ, Gillespie N, Soyer HP, et al. Is teledermoscopy ready to replace face-to-face examinations for the early detection of skin cancer? Consumer views, technology acceptance, and satisfaction with care. Dermatology. 2020; 236(2):90-6.

5 Finnane A, Dallest K, Janda M, Soyer HP. Teledermatology for the diagnosis and management of skin cancer: a systematic review. JAMA Dermatol. 2017;153(3):319-27.

6 Chuchu N, Dinnes J, Takwoingi Y, Matin RN, Bayliss SE, Davenport C, et al. Teledermatology for diagnosing skin cancer in adults. Cochrane Database Syst Rev. 2018;12(12): CD013193.
7 Fogel AL, Sarin KY. A survey of direct-toconsumer teledermatology services available to US patients: explosive growth, opportunities and controversy. J Telemed Telecare. 2017;23(1):19-25.

8 Snoswell CL, Caffery LJ. Current economic evidence for teledermoscopy. Curr Derm Rep. 2020;9(2):131-5.

9 Vestergaard T, Prasad S, Schuster A, Laurinaviciene R, Andersen M, Bygum A. Diagnostic accuracy and interobserver concordance: teledermoscopy of 600 suspicious skin lesions in Southern Denmark. J Eur Acad Dermatol Venereol. 2020;34(7):1601-8. 
10 Gilling S, Mortz CG, Vestergaard T. Patient satisfaction and expectations regarding mobile teledermoscopy in general practice for $\mathrm{di}$ agnosis of non-melanoma skin cancer and malignant melanoma. Acta Derm Venereol. 2020;100(6-7):adv00117.

11 Spinks J, Janda M, Soyer HP, Whitty JA. Consumer preferences for teledermoscopy screening to detect melanoma early. J Telemed Telecare. 2016;22(1):39-46.

12 Snoswell CL, Whitty JA, Caffery LJ, Loescher LJ, Gillespie N, Janda M. Direct-to-consumer mobile teledermoscopy for skin cancer screening: preliminary results demonstrating willingness-to-pay in Australia. J Telemed Telecare. 2018;24(10):683-9.

13 Koh U, Horsham C, Soyer HP, Loescher LJ, Gillespie N, Vagenas D, et al. Consumer acceptance and expectations of a mobile health application to photograph skin lesions for early detection of melanoma. Dermatology. 2019;235(1):4-10.

14 Horsham C, Loescher LJ, Whiteman DC, Soyer HP, Janda M. Consumer acceptance of patient-performed mobile teledermoscopy for the early detection of melanoma. Br J Dermatol. 2016;175(6):1301-10.

15 de Bekker-Grob EW, Ryan M, Gerard K. Discrete choice experiments in health economics: a review of the literature. Health Econ. 2012;21(2):145-72.

16 Janda M, Horsham C, Koh U, Gillespie N, Loescher LJ, Vagenas D, et al. Redesigning skin cancer early detection and care using a new mobile health application: protocol of the
SKIN research project, a randomised controlled trial. Dermatology. 2019;235(1):11-8.

17 Janda M, Horsham C, Vagenas D, Loescher LJ, Gillespie N, Koh U, et al. Accuracy of mobile digital teledermoscopy for skin self-examinations in adults at high risk of skin cancer: an open-label, randomised controlled trial. Lancet Digit Health. 2020;2(3):e129-37.

18 Ryan M, Gerard K, Amaya-Amaya M. Using discrete choice experiments to value health and health care. Springer Science \& Business Media; 2007.

19 McFadden D. Conditional logit analysis of qualitative choice behavior. 1973. https://eml. berkeley.edu/reprints/mcfadden/zarembka. pdf.

20 Breidert C, Hahsler M, Reutterer T. A review of methods for measuring willingness-to-pay. Innov Mark. 2006;2(4):8-32.

21 Bayoumi AM. The measurement of contingent valuation for health economics. Pharmacoeconomics. 2004;22(11):691-700.

22 Snoswell C, Smith AC, Scuffham PA, Whitty JA. Economic evaluation strategies in telehealth: obtaining a more holistic valuation of telehealth interventions. J Telemed Telecare. 2016;23(9):792-6.

23 Ryan M, Farrar S. Using conjoint analysis to elicit preferences for health care. BMJ. 2000; 320(7248):1530-3.

24 Johnson R, Orme B. Sample size issues for conjoint analysis. In: Orme BK. Getting started with conjoint analysis: strategies for product design and pricing research. Madison: Research Publishers LLC; 2010. p. 57-66.
25 Hole AR. Fitting mixed logit models by using maximum simulated likelihood. Stata J. 2007; 7(3):388-401.

26 Hauber AB, González JM, Groothuis-Oudshoorn CG, Prior T, Marshall DA, Cunningham C, et al. Statistical methods for the analysis of discrete choice experiments: a report of the ISPOR Conjoint Analysis Good Research Practices Task Force. Value Health. 2016; 19(4):300-15.

27 Hole A. WTP: Stata module to estimate confidence intervals for willingness to pay measures. 2007. https://econpapers.repec.org/ software/bocbocode/s456808.htm.

28 Snoswell CL, Whitty JA, Caffery LJ, Finnane A, Soyer HP. What do Australian dermatologists expect to be paid for store-and-forward teledermoscopy? A preliminary investigation. J Telemed Telecare. 2019;25(7):438-44.

29 Wu X, Oliveria SA, Yagerman S, Chen L, DeFazio J, Braun R, et al. Feasibility and efficacy of patient-initiated mobile teledermoscopy for short-term monitoring of clinically atypical nevi. JAMA Dermatol. 2015;151(5):48996.

30 Snoswell CL, Caffery LJ, Whitty JA, Soyer HP, Gordon LG. Cost-effectiveness of skin cancer referral and consultation using teledermoscopy in Australia. JAMA Dermatol. 2018; 154(6):694-700.

31 Lancsar E, Savage E. Deriving welfare measures from discrete choice experiments: inconsistency between current methods and random utility and welfare theory. Health Econ. 2004;13(9):901-7. 